\title{
Nitrogen Dioxide Fumigation for Microbial Control on Unshelled Peanuts*
}

\author{
Sookyung Oh, Rippy Singh, Yong-Biao Liü \\ U.S. Department of Agriculture, Agricultural Research Service, Crop Improvement and Protection Unit, Salinas, USA \\ Email: "yongbiao.liu@usda.gov
}

How to cite this paper: Oh, S., Singh, R. and Liu, Y.-B. (2020) Nitrogen Dioxide Fumigation for Microbial Control on Unshelled Peanuts. Agricultural Sciences, 11, 1159-1169.

https://doi.org/10.4236/as.2020.1112076

Received: November 15, 2020

Accepted: December 18, 2020

Published: December 21, 2020

Copyright $\odot 2020$ by author(s) and Scientific Research Publishing Inc. This work is licensed under the Creative Commons Attribution-NonCommercial International License (CC BY-NC 4.0). http://creativecommons.org/licenses/by-nc/4.0/ (c) (i) (s) Open Access

\begin{abstract}
Stored peanuts often need treatments to control microbial infections as well as insects to maintain postharvest quality. Nitric oxide (NO) is a recently discovered fumigant for postharvest pest control. NO fumigation must be conducted under ultralow oxygen condition to preserve $\mathrm{NO}$ and always contains $\mathrm{NO}_{2}$ due to $\mathrm{NO}$ reaction with oxygen and $\mathrm{NO}_{2}$ has antimicrobial property. Therefore, NO fumigation has potential to control both pests and pathogens. In this study, we evaluated antimicrobial effects of $\mathrm{NO}_{2}$ fumigation on unpasteurized unshelled peanuts. Peanuts were fumigated with $0.3 \%$, $1.0 \%$, and $3.0 \% \mathrm{NO}_{2}$ for three days at $25^{\circ} \mathrm{C}$ by injecting $\mathrm{NO}$ gas into glass jars to react with $\mathrm{O}_{2}$ in the atmosphere. After fumigation, wash-off microbial samples were collected from intact peanut samples and, then, cracked open peanut samples with non-selective tryptic soy broth medium. The wash-off samples were then diluted with both the non-selective medium and a fungal-selective potato dextrose broth medium and were tested on GreenLight ${ }^{\text {tw }}$ rapid enumeration test based on oxygen depletion on culture medium. All three $\mathrm{NO}_{2}$ fumigation treatments showed significant antibacterial and antifungal effects on intact peanuts as well as on cracked peanuts with complete inhibition with 3.0\% $\mathrm{NO}_{2}$. Fumigation did not have obvious effects on appearance of skinned peanut kernels. These results suggested that $\mathrm{NO}_{2}$ fumigation has potential to control microbes on stored products, and NO fumigation with the combination of $\mathrm{NO}$ and $\mathrm{NO}_{2}$ has potential to control both insects and microbes on stored products.
\end{abstract}

\section{Keywords}

Nitrogen Dioxide, Nitric Oxide, Postharvest, Fumigation, Microbes, Peanuts

${ }^{*}$ This article reports the results of research only. Mention of proprietary products, trade names or commercial products in this publication is not for the purpose of providing specific information and does not constitute an endorsement or a recommendation by the U.S. Department of Agriculture for its use. The USDA is an equal opportunity provider and employer.

\#Corresponding author. 


\section{Introduction}

Peanut is an important food commodity with annual production of about 45 million metric tons worldwide. U.S. production is fourth largest after China, India, and Nigeria. In 2019, U.S. produced 2,490,220 metric tons of peanuts with market value of $\$ 1$ billion [1] [2]. Peanut production can be affected by pests and diseases during preharvest in the field and postharvest storage and transportation. About 10 to $25 \%$ loss of peanut during postharvest storage has been reported in Asia [3]. Stored peanuts often face infection by microorganisms, resulting in reductions in quality and market value, and increased health risks. Infected peanuts and its processed products have been associated with foodborne illnesses, caused by pathogenic bacteria, such as Salmonella and Listeria species [4] [5]. Fungal infection in peanuts may occur from the field and continue through the storage and common storage fungal pathogens include Fusarium, Penicillium, and Aspergillus species [6]. Among them, Aspergillus flavus infection is a major threat to food safety due to its carcinogenic aflatoxin production [6]. Microbial infection of peanuts can be promoted by high temperature, high relative humidity, mechanical damage, and insect infestation during postharvest storage.

Insect infestation is also a serious issue during the storage of peanuts. The Indianmeal moth (Plodia interpunctella), the red flour beetle (Tribolium castaneum), and the rice moth (Corcyra cephalonica) are key insect pests on stored peanuts in U.S. and elsewhere, and there is a strong correlation between insect infestation and fungal infection in peanuts [6] [7]. Insect infestation also causes increases in moisture and heat and, thereby, facilitates fungus growth. Therefore, a postharvest treatment that controls both insects and microorganisms would be highly desirable. To control insects or fungi in stored peanuts, insecticides, fungicides, and chemical fumigation have been used [7]. The commonly used fumigant methyl bromide has been phased out due to its ozone-depleting effects [8]. Phosphine, as a main replacement of methyl bromide, has often been used on stored peanuts [7]. However, phosphine fumigation has long treatment time and is not effective against some insects due to tolerance or resistance [8].

Nitric oxide (NO) is a recently discovered fumigant for postharvest pest control [9] [10]. Because $\mathrm{NO}$ reacts with $\mathrm{O}_{2}$ spontaneously to form nitrogen dioxide $\left(\mathrm{NO}_{2}\right)$ [11], NO fumigation must be conducted under ultralow level of oxygen (ULO) environment to preserve $\mathrm{NO}$, and also be terminated with $\mathrm{N}_{2}$-flushing to prevent $\mathrm{NO}$ from reacting with $\mathrm{O}_{2}$ to form $\mathrm{NO}_{2}[12] . \mathrm{NO}_{2}$ formation at the end of NO fumigation can cause injuries to fresh products [12] [13] and lead to higher residues of nitrate, nitrite, and $\mathrm{NO}_{2}$ [14].

Both $\mathrm{NO}$ and $\mathrm{NO}_{2}$ gases have antimicrobial properties. $\mathrm{NO}$ was reported to cause cellular damage in bacteria and fungi through DNA-, lipid-, or protein-binding [15] [16] [17] [18]. $\mathrm{NO}_{2}$ can also inactivate microorganisms by inducing breakage of single-strand DNA and cell wall components [19] [20] [21]. $\mathrm{NO}_{2}$ gas has been used to sterilize medical devices and instruments [22]. We 
previously demonstrated that fumigations with $1.0 \% \mathrm{NO}$ or $0.1 \% \mathrm{NO}_{2}$ completely control Aspergillus flavus spores trapped on nitrocellulose membranes as in vitro approaches [23] and control microbes on stored almonds [24]. NO fumigation was also reported to be effective in controlling microbes on dried apricots [25]. Effectiveness of those fumigations in inactivation of microorganisms on most other agricultural commodities has not been studied.

$\mathrm{NO}$ fumigation with proper levels of $\mathrm{NO}$ and $\mathrm{NO}_{2}$ for controlling insects and microbes in a single fumigation treatment would be highly desirable. Efficacy of NO fumigation for controlling stored product insects has been demonstrated earlier [9]. In this study, we performed in vivo $\mathrm{NO}_{2}$ fumigation tests to demonstrate the microbicidal effect of $\mathrm{NO}_{2}$ on unpasteurized unshelled peanuts.

\section{Materials and Methods}

\subsection{Gas and Peanuts}

Compressed nitric oxide (NO, >99.5\%) was purchased from Praxair, Inc. (Salinas, CA). Unpasteurized unshelled Virginia peanuts grown by Wakefield Peanut Company (Wakefield, VA) were obtained from an online store and stored in a plastic bag at room temperature.

\section{2. $\mathrm{NO}_{2}$ Fumigation Procedures}

A group of 10 peanuts, wrapped in Kimwipes tissue, was placed in a 1.9-liter glass jar for fumigation treatment. NO gas was injected into a treatment jar with the normal atmosphere to react with $\mathrm{O}_{2}$ to form $\mathrm{NO}_{2}$. Fumigation treatments with $0.0 \%$ (Control), $0.3 \%, 1.0 \%$, and $3.0 \% \mathrm{NO}_{2}$ were tested by injecting proper volumes of $\mathrm{NO}$ gases into the fumigation jars under ambient atmosphere. The fumigation jars were then placed at $25^{\circ} \mathrm{C}$ in an environmental chamber for three days to complete the treatments. To terminate fumigation, the jars were vented in a fume hood for 30 minutes. Each treatment was replicated four times.

\subsection{Preparation of Microbial Wash-Off Samples from Peanuts}

The 10 unshelled peanuts from each treatment were placed in a Ziplock freezer storage bag $(17.8 \mathrm{~cm} \times 18.9 \mathrm{~cm}$, New Brunswick, NJ) with $100 \mathrm{~mL}$ Tryptic Soy Broth (TSB, Thermo Fisher Scientific, Waltham, MA) and the peanut samples were washed by swirling the bag for five minutes at room temperature. A $10 \mathrm{~mL}$ aliquot of wash-off solution was taken in order to determine the microbial loads on outside surfaces of intact unshelled peanuts.

The peanuts in the remaining $90 \mathrm{~mL}$ TSB were cracked to open and then further washed by swirling the bag for five minutes. A $10 \mathrm{~mL}$ aliquot of wash-off solution was taken for determination of total microbial loads of the peanuts.

Two $4 \mathrm{~mL}$ aliquots of each sample described above were diluted 10 times for enumeration. One $4 \mathrm{~mL}$ aliquot of each sample was diluted with non-selective TSB medium in order to determine total microbial loads (bacteria and fungi). The second $4 \mathrm{~mL}$ aliquot of each sample was diluted with a selective Potato Dex- 
trose Broth (PDB, Alpha Biosciences, Baltimore, MD), supplemented with 100 $\mathrm{mg} / \mathrm{L}$ of chloramphenicol (RPI, Mount Prospect, IL) in order to determine the fungal load.

\subsection{Enumeration Test Using GreenLight ${ }^{\mathrm{TM}}$ Systems}

GreenLight $^{\mathrm{TM}}$ rapid enumeration test (930 series, MOCON, Minneapolis, MN) was used for the enumeration of microbial loads in diluted wash-off solutions of peanuts following previously described protocols [24] [26]. This system measures the length of time for dissolved oxygen in the sample medium in a special APCheck $^{\mathrm{TM}}$ vial (15 mL capacity, Oculer, Tipperary, Ireland), to decline to a threshold level due to aerobic metabolic activities of microbes. The vial is transparent and has an oxygen sensor at the bottom that changes color in response to dissolved oxygen level changes in the medium. The color of the oxygen sensor is measured by a detector positioned below the vial in the system to determine dissolved oxygen levels in the medium. Each vial contained $10 \mathrm{~mL}$ of one of the 1:10 diluted samples for enumeration. Both TSB and PDB diluted samples were used in enumerations tests to determine combined load of bacteria and fungi and fungi only, respectively. The total microbial load enumerations were conducted at $32^{\circ} \mathrm{C}$ for 19 hours, while the fungal load enumerations were done at $25^{\circ} \mathrm{C}$ for 50 hours.

A reference calibration curve was constructed as a correlation between the times to reach the threshold (Hours) in GreenLight ${ }^{\mathrm{TM}}$ rapid enumeration tests and colony forming units $(\mathrm{CFU} / \mathrm{mL})$ in the classical viable colony counting tests from the same serial dilutions of the original wash-off samples from the control peanuts. For the calibration curve, the original wash-off solutions from controls were prepared using TSB and PDB for combination of bacteria and fungi and fungi only, respectively, as described above and diluted serially up to $1 / 100,000$ dilutions with TSB, and up to 1/1000 dilutions with PDB. Enumerations of the control samples were done in the same manner as the fumigated samples described above. Classical viable colony counting was done using $100 \mu \mathrm{L}$ aliquots of dilutions with TSB incubated on TSB agar plates at $32^{\circ} \mathrm{C}$ for two days, and $100 \mu \mathrm{L}$ aliquots of dilutions with PDB were incubated on PDB agar plates at $25^{\circ} \mathrm{C}$ for three days.

\subsection{Data Analysis}

Colony numbers of microorganisms from fumigation samples were $\log 10$ transformed prior to one-way analysis of variance (ANOVA). Tukey HSD test ( $P$ $=0.05)$ and the two-tailed unpaired Student's $t$-test were used to compare multiple and paired means. The JMP statistical discovery software was used for all statistical analyses [27]. Relative colony reductions for fumigation treatments were calculated based on colony numbers from control samples, assuming same numbers of expected colony formation for all treatments and the control if there were no treatment effects. 


\section{Results}

$\mathrm{NO}_{2}$ fumigation inhibited microorganisms on outer surfaces and inside shells of unshelled peanuts and the effect increased with increasing $\mathrm{NO}_{2}$ concentration. When wash-off samples from intact peanuts were diluted with nonselective TSB medium, the GreenLight ${ }^{\mathrm{TM}}$ enumeration showed that fumigation with $0.3 \%$, $1.0 \%$, and $3.0 \% \mathrm{NO}_{2}$ had $8.3 \%, 0.0 \%$, and $0.0 \%$ colony formation, respectively, relative to colony formation from the control (Figure $1(\mathrm{a})$ ). There were significant differences in colony formation among treatments $(F=252.123$; df $=3,44$; $P<0.0001)$. TSB dilutions of cracked peanut wash-off samples for fumigations with $0.3 \%, 1.0 \%$, and $3.0 \% \mathrm{NO}_{2}$ yielded $6.2 \%, 0.0 \%$, and $0.0 \%$ colony formation, respectively, relative to the control (Figure $1(\mathrm{a})$ ). There were significant differences in colony formation among treatments $(F=320.362 ; \mathrm{df}=3,44 ; P<$ $0.0001)$. The microbial load on cracked control peanuts was significantly higher (354.0\%) than those from intact control peanuts $(F=4.477$; $\mathrm{df}=1,22 ; P=$ 0.0459 ) (Figure 1(a)).

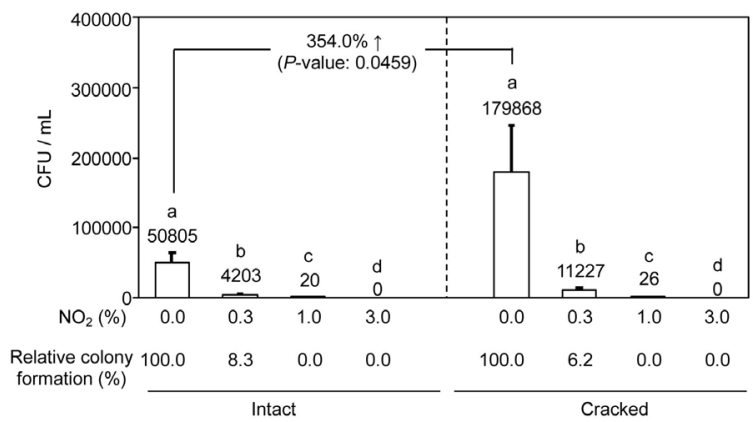

(a)

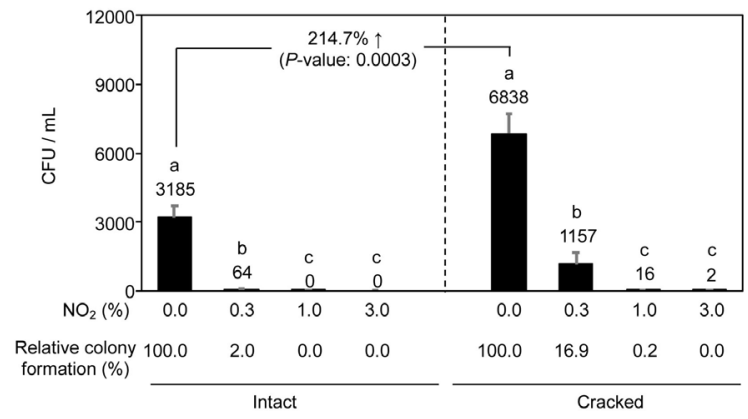

(b)

Figure 1. Effects of 3-day $\mathrm{NO}_{2}$ fumigations on microbial loads on unshelled peanuts at $25^{\circ} \mathrm{C}$. Wash-off samples from unshelled peanut samples were taken before and after peanuts were cracked open. Wash-off samples diluted with non-selective tryptic soy broth (a) and fungal-selective potato dextrose broth supplemented with $100 \mathrm{mg} / \mathrm{L}$ of chloramphenicol (b) were subjected to GreenLight ${ }^{\mathrm{TM}}$ rapid enumeration tests to determine colony forming units (CFU) of bacteria + fungi and fungi only, respectively. CFU data were transformed by Log10 prior to one-way ANOVA with Tukey HSD test $(P=0.05)$ and two-tailed unpaired Student's $t$-test. Means of CFU/mL (on top of bars) with the same letter were not significantly different. Relative colony formation (\%) for each treatment was calculated assuming CFU of control as $100 \%$. 
When fungal-selective PDB medium was used to dilute wash-off samples of intact peanuts for GreenLight ${ }^{\mathrm{TM}}$ enumeration, fumigation with $0.3 \%, 1.0 \%$, and $3.0 \% \mathrm{NO}_{2}$ resulted in $2.0 \%, 0.0 \%$, and $0.0 \%$ colony formation, respectively, relative to the control (Figure 1(b)). There were significant differences in colony formation among treatments $(F=369.358 ; \mathrm{df}=3,44 ; P<0.0001)$. PDB dilutions of wash-off samples from cracked peanuts for $0.3 \%, 1.0 \%$, and $3.0 \% \mathrm{NO}_{2}$ fumigation treatment had $16.9 \%, 0.2 \%$, and $0.0 \%$ colony formation, respectively, relative to the control (Figure 1(b)). There were significant differences in colony formation among treatments $(F=91.5142 ; \mathrm{df}=3,44 ; P<0.0001)$. The fungal load from cracked control peanuts was significantly higher $(214.7 \%)$ than that from intact control peanuts ( $F=18.7364 ; \mathrm{df}=1,22 ; P=0.0003$ ) (Figure $1(b)$ ).

The calibration curve of correlation between times of reaching the threshold in GreenLight ${ }^{\mathrm{TM}}$ rapid enumeration test and colony forming units $(\mathrm{CFU} / \mathrm{mL})$ in classical plate colony counting for serially diluted wash-off samples from control peanuts was plotted for both TSB and PDB media. There were strong and significant correlations between those two parameters in both types of media (TSB: $y$ $\left.=-1.2374 \mathrm{x}+8.1698, \mathrm{R}^{2}=0.9432 ; \mathrm{PDB}: \mathrm{y}=-5.8260 \mathrm{x}+30.3214, \mathrm{R}^{2}=0.9219\right)$ (Figure 2).

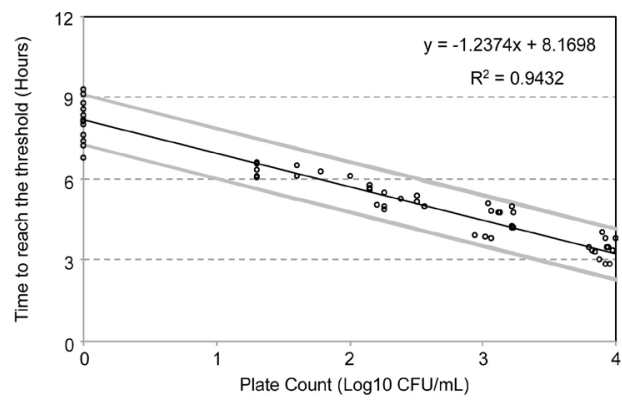

(a)

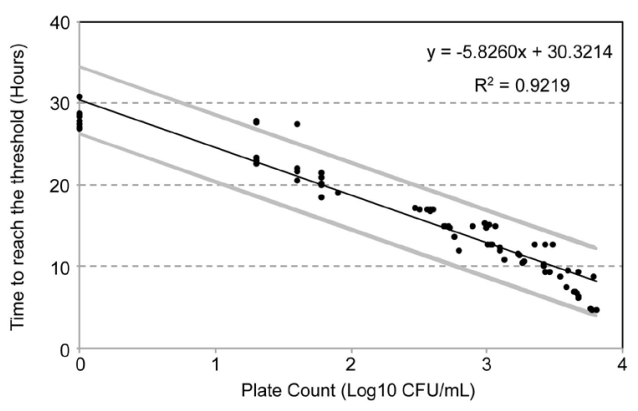

(b)

Figure 2. Linear regression time to result (Hours) in GreenLight ${ }^{\text {t"m }}$ rapid enumeration test on colony forming units $(\log 10 \mathrm{CFU} / \mathrm{mL}$ ) in the classical colony counting test. (a) Serial dilutions of wash-off samples from control peanuts were prepared using non-selective tryptic soy broth and tested at $32^{\circ} \mathrm{C}$; (b) Serial dilutions of wash-off samples from control peanuts were prepared using fungal-selective potato dextrose broth supplemented with $100 \mathrm{mg} / \mathrm{L}$ of chloramphenicol and tested at $25^{\circ} \mathrm{C}$. Thick gray lines represent lower and upper $95 \%$ prediction intervals. Pearson correlation coefficients were (a) $-0.9712(P<$ $0.0001)$ and (b) $-0.9602(P<0.0001)$. 
Surfaces of unshelled peanuts from fumigation treatments appeared to be slightly darker compared with control peanuts, but undistinguishable among the three fumigation treatments (Figure 3). Shelled peanuts from fumigated unshelled peanuts were also darker compared with control peanuts, and the color became progressively darker with increasing concentrations of $\mathrm{NO}_{2}$. There was no difference in color of skinned peanuts among fumigation treatments and the control.

\section{Discussion}

$\mathrm{NO}_{2}$ fumigation was effective in controlling bacteria and fungi on surfaces and insides of unshelled peanuts. Three-day fumigations with $\geq 1.0 \% \mathrm{NO}_{2}$ resulted in almost complete control of microorganisms on peanuts (Figure 1). The unshelled peanuts used in $\mathrm{NO}_{2}$ fumigation were inspected prior to fumigation tests and only intact peanuts without any damage were used. The significantly higher $\mathrm{CFU} / \mathrm{mL}$ from cracked peanuts than those for intact peanuts indicated that there were significant loads of bacteria and fungi inside peanuts.

Fungi are associated with peanuts through seed development, harvesting, and storage of peanuts, and they often cause poor germination, mustiness, and mycotoxin contamination [28]. Storage fungi on peanuts include species of Aspergillus, Penicillium, Rhizopus, and Fusarium [29]. Aspergillus flavus is most important among them due to its carcinogenic aflatoxin production. Almost complete control of all bacteria and fungi were achieved in the current study. Therefore, it is reasonable to assume that $\mathrm{NO}_{2}$ fumigation is effective against all major fungal contaminants listed above. However, these encouraging results were based on small laboratory fumigation tests. Larger-scale fumigation tests are needed to verify efficacy of small laboratory fumigations and develop practical $\mathrm{NO}_{2}$ fumigation tests.

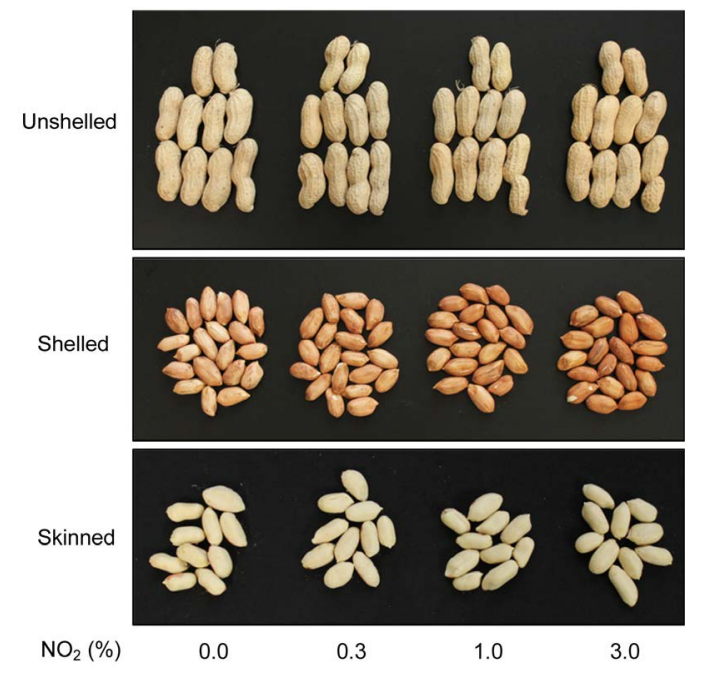

Figure 3. Effects of $\mathrm{NO}_{2}$ fumigation on visual appearance of unshelled, shelled, and skinned peanuts. Unpasteurized, unshelled peanuts were fumigated with $0.3 \%, 1.0 \%$, and $3.0 \%$ of $\mathrm{NO}_{2}$ for three days at $25^{\circ} \mathrm{C}$. 
Antimicrobial effects of $\mathrm{NO}_{2}$ fumigation on peanuts in the current study are consistent with previous findings of antifungal effects in an in vitro study [23] and antimicrobial effects on stored almond [24]. Fumigations with $0.1 \% \mathrm{NO}_{2}$ and $0.3 \% \mathrm{NO}_{2}$ are sufficient for the complete control of fungi on almonds [24]. For unshelled peanuts, however, fumigations with $\geq 1.0 \% \mathrm{NO}_{2}$ were required for the complete control of fungi, indicating the need to develop product-specific fumigation treatments for microbial control. Peanut shells are composed of woody protective layers of fibers with carbohydrates, lipids, and phenolic compounds [30], and this characteristic feature could function as a physical barrier protecting microbes from $\mathrm{NO}_{2}$ fumigation.

NO fumigation is effective in controlling insects and mites on various agricultural commodities [9] [10] [31]. Among them, bulb mites on artificially infested unshelled peanuts are completely controlled by one-day fumigation with $2.0 \% \mathrm{NO}$ at $20^{\circ} \mathrm{C}$ [32]. Unlike $\mathrm{NO}_{2}$ fumigation, $\mathrm{NO}$ fumigation must be performed under ultralow oxygen conditions to preserve $\mathrm{NO}$ as NO reacts spontaneously with oxygen to form $\mathrm{NO}_{2}$. Because complete removal of oxygen is impractical in commercial fumigation setting, $\mathrm{NO}$ fumigation always contains $\mathrm{NO}_{2}$. By controlling $\mathrm{O}_{2}$ levels with initial $\mathrm{N}_{2}$ gas flushing, $\mathrm{NO}$ fumigation can have desired levels of $\mathrm{NO}$ for pest control and $\mathrm{NO}_{2}$ for microbial control. Therefore, a single fumigation treatment with a desirable $\mathrm{NO}_{2}+\mathrm{NO}$ combination may control both microbes and pests on peanuts. This fumigation strategy would be practical and economical because stored peanuts often face both pest infestation and microbial infection. Insect pests promote fungal entry and spread in peanuts and insect infestation is correlated with fungal infection [6].

Several fumigants have been used to control pests and microbes on stored peanuts. Methyl bromide fumigation is effective against pests and pathogens, and is effective in controlling red flour beetles in stored peanuts [33]. However, it is no longer available due to its destructive effects on atmospheric ozone. Phosphine fumigation is primarily used for postharvest pest control, although it was also reported that a seven-day phosphine fumigation controlled Aspergillus species and aflatoxin production on peanuts [34]. Phosphine, however, is a slowacting fumigant and phosphine fumigation can take more than 10 days to control some stored product insects [8] [35]. Some insects have developed resistance to phosphine [36]. Fumigation with propylene oxide is effective in controlling Indianmeal moth on peanuts, but this fumigant is challenging due to its high flammability at concentrations from $3 \%$ to $37 \%$ in the air [37].

In conclusion, $\mathrm{NO}_{2}$ fumigation was demonstrated to be effective against microbes on and inside unshelled peanuts and, therefore, has potential to control microbes on stored peanuts as well as other stored products. Fumigation with $\mathrm{NO}+\mathrm{NO}_{2}$, therefore, has potential to be an effective and safe alternative to methyl bromide for control of insects and microbes on stored peanuts and other stored products. More research is warranted to develop practical fumigation treatments with $\mathrm{NO}_{2}$ and $\mathrm{NO}+\mathrm{NO}_{2}$ for control of microbes and both insects 
and microbes on stored products.

\section{Acknowledgements}

We thank T. Masuda for technical assistance. This study was supported in part by a Technical Assistance for Specialty Crops Program grant (TASC-C2020-01) from U.S. Department of Agriculture, Foreign Agricultural Services.

\section{Conflicts of Interest}

The authors declare no conflicts of interest regarding the publication of this paper.

\section{References}

[1] Schnepf, R. (2016) U.S. Peanut Program and Issues (R44156). Congressional Research Service, Washington DC.

[2] United States Department of Agriculture (2019) Peanut Stocks and Processing. https://www.nass.usda.gov/Publications/Todays_Reports/reports/pnst1219.pdf

[3] Azeemoddin, G. (1993) Post Harvest Technology of Oilseeds. National Seminar on “Oilseeds Research and Development in India: Status and Strategies", Hyderabad, 2-5 August 1993, 231.

[4] Cavallaro, E., Date, K., Medus, C., Meyer, S., Miller, B., Kim, C., Nowicki, S., Cosgrove, S., Sweat, D., Phan, Q., Flint, J., Daly, E.R., Adams, J., Hyytia-Trees, E., Gerner-Smidt, P., Hoekstra, R.M., Schwensohn, C., Langer, A., Sodha, S.V., Rogers, M.C., Angulo, F.J., Tauxe, R.V., Williams, I.T. and Barton Behravesh, C. (2011) Salmonella typhimurium Infections Associated with Peanut Products. New England Journal of Medicine, 365, 601-610. https://doi.org/10.1056/NEJMoa1011208

[5] Uçkun, O. and Var, I. (2018) Microbiological Quality of Peanuts: From Field to Consumption. Sustainable Food Production, 4, 31-39.

https://doi.org/10.18052/www.scipress.com/SFP.4.31

[6] Santos, F.D., Medina, P.F., Lourenção, A.L., Parisi, J.J.D. and Godoy, I.J.D. (2016) Damage Caused by Fungi and Insects to Stored Peanut Seeds before Processing. Bragantia, 75, 184-192. http://dx.doi.org/10.1590/1678-4499.182

[7] Smith, D.T. and Holloway, R. (2003) Stored Peanut Pest Management Strategic Plan. https://ipmdata.ipmcenters.org/documents/pmsps/TXstoredpeanut.pdf

[8] Fields, P.G. and White, N.D.G. (2002) Alternatives to Methyl Bromide Treatments for Stored Product and Quarantine Insects. Annual Review of Entomology, 47, 331-359. https://doi.org/10.1146/annurev.ento.47.091201.145217

[9] Liu, Y.-B. (2013) Nitric Oxide as a Potent Fumigant for Postharvest Pest Control. Journal of Economic Entomology, 106, 2267-2274. https://doi.org/10.1603/EC13249

[10] Liu, Y.-B. and Yang, X. (2016) Prospect of Nitric Oxide as a New Fumigant for Postharvest Insect Control. Proceedings of the 10 th International Conference on Controlled Atmosphere and Fumigation in Stored Products, New Delhi, 7-11 November 2016, 161-166.

[11] Beckman, J.S. and Koppenol, W.H. (1996) Nitric Oxide, Superoxide, and Peroxynitrite: The Good, the Bad, and the Ugly. American Journal of Physiology, 271, C1424-C1437. https://doi.org/10.1152/ajpcell.1996.271.5.C1424

[12] Liu, Y.-B., Yang, X. and Masuda, T. (2017) Procedures of Laboratory Fumigation 
for Insect Control with Nitric Oxide Gas. Journal of Visualized Experiments, 129, e56309. https://dx.doi.org/10.3791/56309

[13] Liu, Y.-B. (2016) Nitric Oxide Fumigation for Control of Western Flower Thrips and Its Safety to Postharvest Quality of Fresh Fruit and Vegetables. Journal of Asia-Pacific Entomology, 19, 1191-1195. https://doi.org/10.1016/j.aspen.2016.10.013

[14] Yang, X. and Liu, Y.-B. (2017) Residual Analysis of Nitric Oxide Fumigation on Fresh Fruit and Vegetables. Postharvest Biology and Technology, 132, 105-108. https://doi.org/10.1016/j.postharvbio.2017.06.006

[15] Wang, J. and Higgins, V.J. (2005) Nitric Oxide Has a Regulatory Effect in the Germination of Conidia of Colletotrichum coccodes. Fungal Genetics and Biology, 42, 284-292. https://doi.org/10.1016/j.fgb.2004.12.006

[16] Ghaffari, A., Miller, C.C., McMullin, B. and Ghahary, A. (2006) Potential Application of Gaseous Nitric Oxide as a Topical Antimicrobial Agent. Nitric Oxide, 14, 21-29. https://doi.org/10.1016/j.niox.2005.08.003

[17] Schairer, D.O., Chouake, J.S., Nosanchuk, J.D. and Friedman, A.J. (2012) The Potential of Nitric Oxide Releasing Therapies as Antimicrobial Agents. Virulence, 3, 271-279. https://doi.org/10.4161/viru.20328

[18] Bang, C.S., Kinnunen, A., Karlsson, M., Onnberg, A. and Soderquist, B. (2014) The Antibacterial Effect of Nitric Oxide Against ESBL-Producing Uropathogenic E. coli Is Improved by Combination with Micronazole and Polymyxin B Nonapeptide. BMC Microbiology, 14, Article No. 65. https://doi.org/10.1186/1471-2180-14-65

[19] Görsdorf, S., Appel, K.E., Engeholm, C. and Obe, G. (1990) Nitrogen Dioxide Induces DNA Single-Strand Breaks in Cultured Chinese Hamster Cells. Carcinogenesis, 11, 37-41. https://doi.org/10.1093/carcin/11.1.37

[20] Lazar, E.E., Wills, R.B., Ho, B.T., Harris, A.M. and Spohr, L.J. (2008) Antifungal Effect of Gaseous Nitric Oxide on Mycelium Growth, Sporulation and Spore Germination of the Postharvest Horticulture Pathogens, Aspergillus niger, Monilinia fructicola and Penicillium italicum. Letters in Applied Microbiology, 46, 688-692.

[21] Depayras, S., Kondakova, T., Merlet-Machour, N., Heipieper, H.J., Barreau, M., Catovic, C., Feuilloley, M., Orange, N. and Duclairoir-Poc, C. (2018) Impact of Gaseous $\mathrm{NO}_{2}$ on $P$. fluorescens Strain in the Membrane Adaptation and Virulence. International Journal of Environmental Impacts, 1, 183-192.

[22] Shomali, M., Opie, D., Avasthi, T. and Trilling, A. (2015) Nitrogen Dioxide Sterilization in Low-Resource Environments: A Feasibility Study. PLoS ONE, 10, e0130043. https://doi.org/10.1371/journal.pone.0130043

[23] Liu, Y.-B., Oh, S. and Jurick II, W.M. (2019) Response of Aspergillus flavus Spores to Nitric Oxide Fumigations in Atmospheres with Different Oxygen Concentrations. Journal of Stored Products Research, 83, 78-83. https://doi.org/10.1016/j.jspr.2019.06.001

[24] Oh, S. and Liu, Y.-B. (2020) Effectiveness of Nitrogen Dioxide Fumigation for Microbial Control on Stored Almonds. Journal of Food Protection, 83, 599-604. https://doi.org/10.4315/0362-028X.JFP-19-281

[25] Chen, Y., Guo, Q., Wei, J., Zhang, J., Zhang, Z., Wang, J. and Wu, B. (2019) Inhibitory Effect and Mechanism of Nitric Oxide (NO) Fumigation on Fungal Disease in Xinjiang Saimaiti Dried Apricots. LWT Food Science and Technology, 116, Article ID: 108507. https://doi.org/10.1016/j.lwt.2019.108507

[26] Lehotová, V., Petruláková, M. and Valík, M. (2016) Application of a New Method to 
Control Microbial Quality of Foods Based on the Detection of Oxygen Consumption. Acta Chimica Slovaca, 9, 19-22. https://doi.org/10.1515/acs-2016-0004

[27] SAS Institute (2012) JMP Statistic Discovery Software v10. SAS Institute, Cary.

[28] Gachomo, E., Mutitu, E. and Kotchoni, O. (2004) Diversity of Fungal Species Associated with Peanuts in Storage and the Levels of Aflatoxins in Infected Samples. International Journal of Agriculture and Biology, 6, 955-959.

[29] Diener, U.L. (1973) Deterioration of Peanut Quality Caused by Fungi. In: Wilson, C.T., Ed., Peanuts-Culture and Use, American Peanut Research and Education Association, Inc., Oklahoma, 523-557.

[30] Adhikari, B., Dhungana, S.K., Ali, M.W., Adhikari, A., Kim, I.-D. and Shin, D.-H. (2018) Antioxidant Activities, Polyphenol, Flavonoid, and Amino Acid Contents in Peanut Shell. Journal of the Saudi Society of Agricultural Sciences, 18, 437-442. https://doi.org/10.1016/j.jssas.2018.02.004

[31] Liu, Y.-B. (2015) Nitric Oxide as a Fumigant for Postharvest Pest Control and Its Safety to Postharvest Quality of Fresh Products. Acta Horticulturae, 1105, 321-328. https://doi.org/10.17660/ActaHortic.2015.1105.46

[32] Liu, Y.-B. (2017) Nitric Oxide Fumigation for Control of Bulb Mites on Flower Bulbs. Journal of Economic Entomology, 110, 2046-2051. https://doi.org/10.1093/jee/tox187

[33] Leesch, J.G., Redlinger, L.M. and Dennis, N.M. (1978) Methyl Bromide Fumigation of Farmers Stock Peanuts in Flat Storage. Peanut Science, 5, 40-43. https://doi.org/10.3146/i0095-3679-5-1-10

[34] De Castro, M.F.P.P.M., Pacheco, I.A., Soares, L.M.V., Furlani, R.P.Z., De Paula, D.C. and Bolonhezi, S. (1996) Warehouse Control of Aspergillus flavus Link and $A$. parasiticus Speare on Peanuts (Arachis hypogaea) by Phosphine Fumigation and Its Effects on Aflatoxin Production. Journal of Food Protection, 59, 407-411. https://doi.org/10.4315/0362-028X-59.4.407

[35] Hole, B.D., Bell, C.H., Mills, K.A. and Goodship, G. (1976) The Toxicity of Phosphine to All Developmental Stages of Thirteen Species of Stored Product Beetles. Journal of Stored Products Research, 12, 235-244. https://doi.org/10.1016/0022-474X(76)90039-4

[36] Chaudhry, M.Q. (1997) A Review of the Mechanisms Involved in the Action of Phosphine as an Insecticide and Phosphine Resistance in Stored-Product Insects. Pesticide Science, 49, 213-228.

[37] Isikber, A.A., Navarro, S., Finkelman, S. and Rindner, M. (2006) Propylene Oxide: A Potential Quarantine and Pre-Shipment Fumigant for Disinfestation of Nuts. Phytoparasitica, 34, 412-419. https://doi.org/10.1007/BF02981028 